\title{
Empowering the immune fate of bone marrow mesenchymal stromal cells: gene and protein changes
}

\author{
Mehdi Najar ${ }^{1} \cdot$ Yassine Ouhaddi $^{1} \cdot$ Fatima Bouhtit $^{2} \cdot$ Rahma Melki $^{2} \cdot$ Hassan Afif $^{1} \cdot$ Noureddine Boukhatem $^{2} \cdot$ \\ Makram Merimi ${ }^{2,3} \cdot$ Hassan Fahmi ${ }^{1}$
}

Received: 24 April 2018 / Revised: 23 October 2018 / Accepted: 7 November 2018 / Published online: 14 November 2018

(c) Springer Nature Switzerland AG 2018

\begin{abstract}
Objective and design Bone marrow mesenchymal stromal cells (BM-MSCs) are referred as a promising immunotherapeutic cell product. New approaches using empowered MSCs should be developed as for the treatment or prevention of different immunological diseases. Such preconditioning by new licensing stimuli will empower the immune fate of BM-MSCs and, therefore, promote a better and more efficient biological. Here, our main goal was to establish the immunological profile of BM-MSCs following inflammatory priming and in particular their capacity to adjust their immune-related proteome and transcriptome.

Material and methods To run this study, we have used BM-MSC cell cultures, a pro-inflammatory cytokine cocktail priming, flow cytometry analysis, qPCR and ELISA techniques.

Results Different expression levels of several immunological mediators such as COX-1, COX-2, LIF, HGF, Gal-1, HO-1, IL-11, IL-8, IL-6 and TGF- $\beta$ were constitutively observed in BM-MSCs. Inflammation priming substantially but differentially modulated the gene and protein expression profiles of these mediators. Thus, expressions of COX-2, LIF, HGF, IL-11, IL-8 and IL-6 were highly increased/induced and those of COX-1, Gal-1, and TGF- $\beta$ were reduced.

Conclusions Collectively, we demonstrated that BM-MSCs are endowed with a specific and modular regulatory machinery which is potentially involved in immunomodulation. Moreover, BM-MSCs are highly sensitive to inflammation and respond to such signal by properly adjusting their gene and protein expression of regulatory factors. Using such preconditioning may empower the immune fate of MSCs and, therefore, enhance their value for cell-based immunotherapy.
\end{abstract}

Keywords Bone marrow $\cdot$ Mesenchymal stromal cells $\cdot$ Immunomodulation $\cdot$ Regulatory mediators $\cdot$ Inflammation priming

Responsible Editor: John Di Battista.

Mehdi Najar

mnajar@ulb.ac.be

Hassan Fahmi

h.fahmi@umontreal.ca

Yassine Ouhaddi

yassine.ouhaddi@gmail.com

Fatima Bouhtit

bouhtitfatima@gmail.com

Rahma Melki

r.melki@ump.ac.ma

Hassan Afif

hassafif@gmail.com

Noureddine Boukhatem

n.boukhatem@ump.ma
Makram Merimi

macmerimi@gmail.com

1 Osteoarthritis Research Unit, University of Montreal Hospital Research Center (CRCHUM), Department of Medicine, University of Montreal, 900 Saint-Denis, R11.424, Montreal, QC H2X 0A9, Canada

2 Laboratory of Physiology, Ethnopharmacology and Genetics, Faculty of Sciences, University Mohammed Premier, Oujda, Morocco

3 Laboratory of Experimental Hematology, Jules Bordet Institute, Université Libre de Bruxelles, Brussels, Belgium 


\section{Introduction}

Mesenchymal stromal cells (MSCs) are multipotent fibroblast-like cells with several interesting properties such as multiline age and immunomodulatory potential. Although MSCs could be isolated from several tissues [1], the bone marrow (BM) is the mostly used source of MSCs for different therapeutic applications [2]. Several mechanisms are described to be involved in the therapeutic properties of MSCs [3]. Although cell reconstitution is an essential component of MSC-based therapy, the therapeutic effect of MSCs is mainly a result of their potent immunoregulatory ability [4]. Data from in vitro and pre-clinical models demonstrate that MSCs suppress activated immune response cells and thus ameliorate the severity of several different experimental immune diseases. In complex human studies, the immunomodulatory efficacy of MSC therapy is, however, not well established [5]. As the molecular mechanisms that mark MSC immunomodulation are not fully resolved, it is of importance to define these effects according to multiple immunobiological criteria [6]. A network of regulatory pathways in parallel to the induction of several regulatory immune cells, converge and compete to establish a tolerogenic state conducive for immunomodulation [7, 8]. BM-MSCs are known to induce proliferative cytokinic and molecular immune-related changes [9]. Profiling the immunoregulatory mediators that are potentially involved in their effects will help to optimize MSC-based therapy. Moreover, as we previously stated [10], exploring MSC immunological profiles in response to inflammation priming is important to ensure efficient and safe MSCbased immunointervention approaches. The development of an inflammatory environment follows any tissue injury and MSCs are exposed to such stimuli in many clinical conditions (e.g. graft-versus-host disease after allogeneic stem cell transplantation). By sensing damaged signals, MSCs migrate to the injured site where they participate in tissue repair. These effects are mainly due to the suppression of local aberrant immune reactions as well as the promotion of resident cell's biological functions through synergistic upregulation of both prosurvival and antiinflammatory factors. This process is tightly regulated and needs to be licensed by inflammation [11]. Based on gene and protein profiling, several regulatory mediators such as PGE 2 (through COX-1 and COX-2), LIF, HGF, Gal-1, HO-1, IL-11, IL-8, IL-6 and TGF- $\beta$ were differentially expressed and modulated by BM-MSCs following inflammation priming. BM-MSCs demonstrated thus a great sensitivity to the inflammatory environment by properly adjusting their immunological profile. Using inflammatory priming to empower MSC immunotherapeutic potential is of great importance for cell-based therapy.

\section{Materials and methods}

\section{Ethical guidelines}

This study was conducted in accordance with the Declaration of Helsinki (1964) and approved by the local ethics committee.

\section{Isolation and culture of BM-MSCs}

Bone marrow samples were harvested from the sternum or iliac crest of healthy donors after giving informed written consent. The isolation procedure, culture condition and characterization of BM-MSCs were performed as previously described [6] and thanks to LTCC (Laboratory of Clinical Cell Therapy) assistance. Briefly, mononuclear cells (MNC) were isolated by density gradient centrifugation (LinfoSep, Biomedics, Madrid, Spain), washed in Hank's buffered salt solution (HBSS, LonzaEurope, Verviers, Belgium) and seeded in culture flasks with Dulbecco's modified Eagle's medium-low glucose (DMEMLG, Lonza) supplemented with 10\% FBS (Sigma-Aldrich), $2 \mathrm{mM}$ L-glutamine and $50 \mathrm{U} / \mathrm{ml}$ penicillin (both from Lonza). Cell cultures were incubated at $37{ }^{\circ} \mathrm{C}$ in $5 \%$ $\mathrm{CO}_{2}$ and $95 \%$ humidified atmosphere. After $48 \mathrm{~h}$, nonadherent cells were removed by washing and medium was changed twice a week. When subconfluency (80-90\%) was achieved, adherent cells were trypsinized (Lonza) and expanded by replating at lower density.

BM-MSC characterization was achieved according to the ISCT criteria and both immunophenotype and multilineage potential were assessed as previously described [6]. Briefly, the multiline age potential was confirmed by culturing BM-MSCs in appropriate induction medium to assess their adipogenic, osteogenic and chondrogenic differentiation capacities. The immunophenotype was determined by flow cytometry analysis using a panel of fluorochrome-labeled monoclonal antibodies against membrane markers.

\section{Inflammation priming of BM-MSCs}

BM-MSCs were analyzed under both constitutive and inflammatory primed conditions. Priming of BM-MSCs was performed by treating cells (overnight) with a proinflammatory cytokine cocktail containing IL- $1 \beta$ (Peprotech, Rocky Hill, NJ, USA) (25 ng/ml), TNF- $\alpha$ (50 ng/ $\mathrm{ml})$, IFN- $\alpha(3000 \mathrm{U} / \mathrm{ml}$ or $10 \mathrm{ng} / \mathrm{ml})$ and IFN- $\gamma(1000 \mathrm{U} /$ $\mathrm{ml}$ or $50 \mathrm{ng} / \mathrm{ml}$ ) (all from Prospec Inc., Rehovot, Israel). After the priming, the medium was removed, the cells were washed and became available for analysis. 


\section{Quantitative real-time PCR (qRT-PCR)}

Total RNA from each cell culture was extracted in a single step using TriPure Isolation Reagent (Roche Applied Science, Vilvoorde, Belgium). Complementary DNA (cDNA) was obtained by means of reverse transcription reaction of $1 \mu \mathrm{g}$ RNA using qScript cDNA SuperMix (Quanta Biosciences, USA) for $5 \mathrm{~min}$ at $25^{\circ} \mathrm{C}, 30 \mathrm{~min}$ at $42{ }^{\circ} \mathrm{C}$ and $5 \mathrm{~min}$ at $85^{\circ} \mathrm{C}$. To avoid potential DNA contamination of our RNA samples, DNase (Promega, Leiden, The Netherlands) treatment was performed. To confirm the absence of DNA contamination, we included a no-reverse transcriptase control during the reverse transcription step. To control variations in input RNA amounts, the GAPDH gene was used as a housekeeping gene to quantify and normalize the results. Real-time PCR was performed on an ABI Prism 7900HT Sequence Detection System (Applied Biosystems, Rotterdam, The Netherlands). We used $25 \mathrm{ng}$ of cDNA in a real-time PCR with SYBR Green PCR Master Mix (Applied Biosystems) and $0.32 \mu \mathrm{mol} / \mathrm{L}$ of gene-specific forward and reverse primers. The primers were designed with Primer Express 2.0 software (Applied Biosystems) or Probe Finder online software (Roche) and sequences are provided in Table 1. In all cases, dissociation curves were generated and the specificity of the PCRs was confirmed. The comparative $\Delta \Delta \mathrm{Ct}$ method was used for the data analysis. To evaluate the fold change, data were normalized with the GAPDH genes to obtain the $\Delta \mathrm{Ct}$ and were after calibrated with the geometric mean of the GAPDH $\Delta \mathrm{Ct}$ to generate the $\Delta \Delta \mathrm{Ct}$. Fold changes were then calculated as fold change $=2^{-\Delta \Delta C_{t}}$.

\section{ELISA procedures}

The protein secretion profile of these immunoregulatory genes was established by ELISA quantification, according to the manufacturer's instructions. Quantitative determination of PGE2, LIF, HGF, IL-11, IL-8, IL-6, TGF- $\beta$ (all from R\&D Systems), and Gal-1 (Antigenix America Inc) was performed using the cell supernatants whereas HO-1 (Enzo Life Sciences) was assessed in cell lysates.

\section{Statistical analysis}

Data are expressed as mean \pm standard error of the mean (SEM). A total number of seven $(n=7)$ independent experiment was performed for each assay. Statistical analysis was performed by use of the Wilcoxon test for paired samples. A value of $P<0.05$ was considered statistically significant.

\section{Results and discussion}

Due to their immunomodulatory properties, BM-MSCs become an attractive and promising tool for different cellbased immunotherapy strategies [2]. Distinct and complex immunoregulatory mechanisms appear to be involved in MSC effects [12]. MSCs are defined as environmentally responsive cells as they are capable of responding to local environmental stimuli with a myriad of beneficial interventions [13]. As such, inflammatory stimuli by critically influencing their immunoregulatory behavior allow MSCs to adequately respond to the context and thereby facilitate the therapeutic issue [4]. Indeed, MSCs must be considered as sensors and switchers of inflammation that are able to adopt a pro-inflammatory or anti-inflammatory profile by

Table 1 qRT-PCR primers

\begin{tabular}{lll}
\hline Transcripts & Forward primer & Reverse primer \\
\hline $\begin{array}{l}\text { House-keeping } \\
\text { GAPDH }\end{array}$ & AATCCCATCACCATCTTCCA & TGGACTCCACGACGTACTCA \\
Immuno-regulatory & & \\
COX-1 & CCTGCAGCTGAAATTTGACCCA & ACCTTGAAGGAGTCAGGCATG \\
COX-2 & GCTCAAACATGATGTTTGCATTC & GCTGGCCCTCGCTTATGA \\
Gal-1 & AAGCTGCCAGATGGATACGAA & CGTCAGCTGCCATGTAGTTGA \\
HGF & CAATGCCCTCTGGTTCCCCTT & AGGCAAAAAGCTGTGTTCGTG \\
HO-1 & TTCTCCGATGGGTCCTTACACT & GGCATAAAGCCCTACAGCAACT \\
LIF & TGAAAACTGCCGGCATCTGA & CTGTGTACTGCCGCCAAGA \\
IL-11 & CCTGTGGGGACATGAACTGT & AGGGTCTGGGGAAACTCG \\
TGF- $\beta$ & GAGGTCACCCGCGTGCTA & TGTGTACTCTGCTTGAACTTGTCATAGA \\
Cytokines & & \\
IL-6 & AAATTCGGTACATCCTCGACGG & GGAAGGTTCAGGTTGTTTTCTGC \\
IL-8 & CTGTTAAATCTGGCAACCCTAGTCT & CAAGGCACAGTGGAACAAGGA \\
\hline
\end{tabular}


interfering with innate and adaptive immune responses both in vitro and in vivo [14]. To mimic inflammation, a cocktail of pro-inflammatory cytokines containing IL-1 $\beta$, TNF- $\alpha$, IFN- $\alpha$ and IFN- $\gamma$ is usually used by our group as it demonstrated its ability to alter several functions of MSCs [15]. Indeed, inflammation priming of MSCs may influence their expression of cellular adhesion molecules, TLR pattern and microRNA profile. These cytokines are those mostly present at inflammatory sites where they act together in modulating different cellular process [16]. Indeed, these cytokines are known to cooperate in regulating the transcription of a large number of genes important for inflammation and immunoregulation $[17,18]$. With this regard, we aimed in this study to evaluate the regulatory transcriptome and proteome of BM-MSCs as well as determine the impact of inflammatory priming on these profiles.

First, a major issue in the field of cellular therapy is to have a well-defined cell product. According to the International Society for Cellular Therapy (ISCT) guidelines [19], we determined the main characteristics of BM-MSCs that are handled. Under microscopic observation, cells in the culture were of fibroblastic-shape with the ability to adhere to plastic culture dish. Inflammation priming had a slight impact on the biology of BM-MSCs as demonstrated by the maintenance of their viability and capacity of cell adherence. Using both appropriate induction medium and specific staining, these cells successfully differentiated into osteoblasts, chondrocytes and adipocytes corroborating thus their multilineage potential (Fig. 1). It is generally believed that MSC-based therapy not only provides a source of cells with which to reconstitute a tissue (cell replacement) but also regulates inflammation and 'empowers' other cells (cell empowerment) to facilitate tissue repair. In the microenvironment of injured tissues, many inflammatory factors, including cytokines such as TNF- $\alpha$, IL- 1 , IFN- $\gamma$ can stimulate the release of a plethora of growth/angiogenic factors (reviewed in [20]). These growth factors orchestrate endothelial cells, fibroblasts as well as stem cells to promote tissue regeneration and repair through enhancing angiogenesis, inhibiting leukocyte transmigration and eliciting intrinsic progenitor cell/stem cell differentiation [21]. As supported by Ryan et al. [22], MSCs are able to avoid allogeneic rejection in humans and in animal models by at least three broad mechanisms (non-immunogenic, modulation of immune cells, creation of a suppressive microenvironment). Thus, we have established the phenotype of BM-MSCs by flow cytometry analysis of a panel of markers as recommended by the ISCT. Flow cytometry analysis confirmed that cells within culture were positive for CD73, CD90 and CD105, but are negative for CD45, CD14, CD19, CD34 and HLA-DR (Fig. 2). Inflammatory priming of BM-MSCs did not alter this phenotype keeping thus the expression levels of these markers unchanged. Indeed, BM-MSCs were negative for CD34 expression as jointly stated by the International Federation for Adipose Therapeutics and Science (IFATS) and the ISCT. Highly variable, CD34 expression is mainly linked to adipose tissue and its functions is still elusive [23, 24]. BM-MSCs were constitutively and highly positive for the two main stromal cell-associated markers CD90 and CD105 that guarantee MSC functionality $[25,26]$. The ectoenzymes CD39 and CD73, mainly involved in the generation of the regulatory adenosine, were distinctly expressed by MSCs and differentially associated with their immunomodulatory effects [27-29]. Concerning hematopoietic markers, BM-MSCs did not show CD14, CD19 and CD45 expression as required for safe and efficient cell-based therapy [30, 31]. After inflammatory challenge, BM-MSCs demonstrated only CD40 induction that is in agreement with previous studies $[32,33]$. In particular, the expression of HLA-DR, which is a marker of immunogenicity, was not induced after inflammatory priming of BM-MSCs [10]. In a recent study comparing the immunological characteristics of MSCs from
Adipogenesis

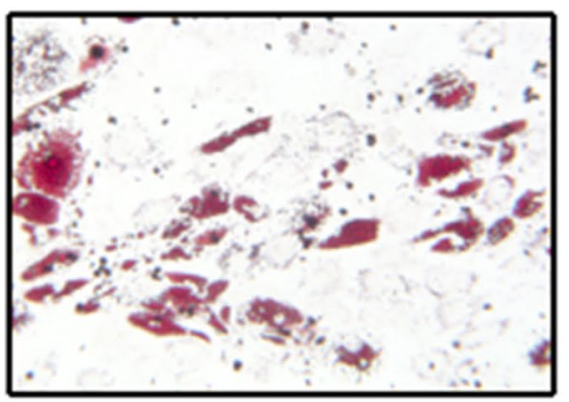

Fig. 1 The differentiation potential of BM-MSCs. Representative example of BM-MSC differentiation into adipocytes (adipogenesis), osteoblasts (osteogenesis) and chondrocytes (chondrogenesis), respectively, demonstrated by the formation of lipid vacuoles (Oil
Osteogenesis

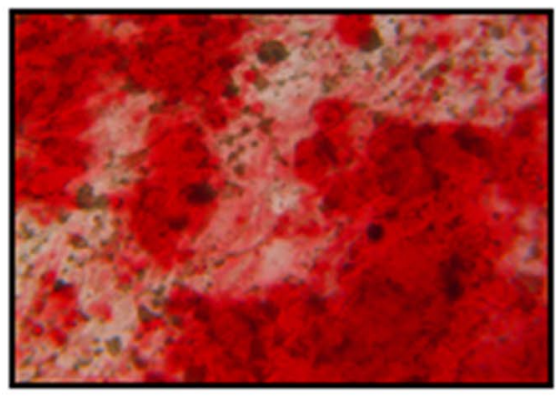

Chondrogenesis

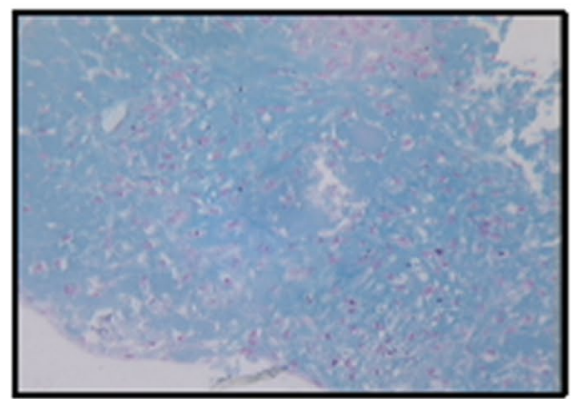

Red O staining), the calcium mineralization (Alizarin Red staining) and the synthesis of proteoglycans (Alcian blue staining). (Color figure online) 

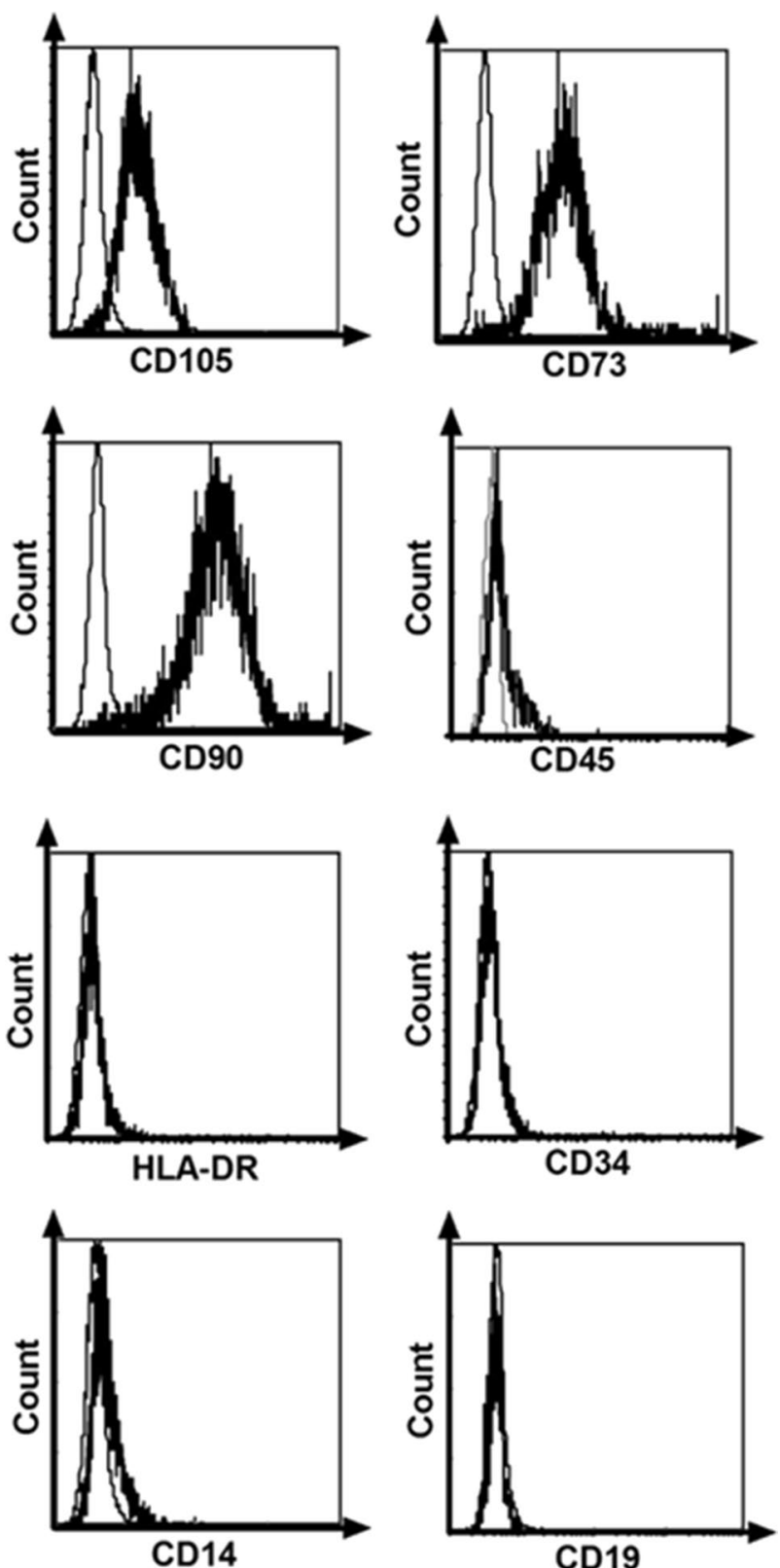

Fig. 2 The phenotype of BM-MSCs. Representative flow cytometry histograms of the main marker used to define BM-MSCs according to ISCT criteria. BM-MSCs were positive for CD105, CD73 and CD90 but negative for CD45, HLA-DR, CD34, CD14 and CD19

periodontal ligament, umbilical cord and adipose tissue, the authors reported minimal expression of HLA-DR after cell priming [34]. They suggest that MSCs pose minimal risk of initiating an allogenic immune response when administered in vivo. Indeed, MSCs are hypo-immunogenic as they lack HLA class II and costimulatory molecule expression. Even though CD40 expression is observed during inflammatory priming, optimal stimulation of lymphocytes requires the activation of the costimulatory pathway [35] that is tightly regulated by a subset of inhibitory molecules [36]. Thus, induction of CD274 (B7-H1 or PD-L1), known to negatively regulate T-cell activation, is observed on MSCs in an inflammatory setting [37]. These results demonstrated that BM-MSCs, even in an inflammatory context, might be considered non-immunogenic as they are not able to elicit an immune response due to the lack of expression of the major components involved in T-cell activation (antigen presentation, co-stimulation and cytokine secretion). Accordingly, MSCs are not 'immune privileged' but should be considered 'immune evasive', which could be promoted by applying strategies that induce MSC expression of immune-evasive factors [38].

In parallel to this 'immune evasive' state that allows MSCs to be tolerated by the recipient host and not rejected, these cells display strong immunomodulatory effects that target the immunobiology of almost all immune cells. Several regulatory molecules and factors have been described to partially underline these mechanisms and are still to be more defined [39]. In this study, we established a gene (Fig. 3) and protein (Fig. 4) profiling of several immunoregulatory mediators potentially involved in BM-MSC immunomodulation. Under inflammatory conditions, MSCs are primed to become more immunomodulatory in inhibiting immune response by displaying a high level of immunoregulatory factors (e.g. PGE2, Galectin, etc.). This potent secretome is likely to work as a network where interdependent and cross-regulated mechanisms co-exist in parallel to several feedback loops competing altogether to establish a tolerogenic state [7]. In the same time, these primed MSCs will also secrete great amounts of cyto-protective molecules (e.g. HO-1) and growth factors (e.g. HGF, TGF, etc.) which can facilitate tissue repair through their effects on endothelial cells and fibroblasts, as well as tissue progenitor cells, at sites of damaged tissue [40]. The expression profile of PGE 2 (through COX-1 and COX-2), LIF, HGF, Gal-1, HO-1, IL-11, IL-8, IL-6 and TGF- $\beta$ as well as their modulation were critically dependent on inflammation priming. Of interest, the sensitivity of MSCs to inflammatory priming seems to be source dependent as differences in the response of MSCs have been reported. Separately, IFN- $\gamma$ and TNF- $\alpha$, differentially affected the immune properties of BM-MSCs and Wharton's jelly-MSCs (WJ-MSCs) [41]. Crop et al. have revealed that priming of adipose tissue-derived MSCs with a pro-inflammatory cytokine cocktail (IFN- $\gamma, \mathrm{TNF}-\alpha$ and IL-6) altered their gene expression and function and, in particular, induced expression of CD40 and MHC II [42]. As previously evidenced [43, 44], IFN- $\gamma$ has a significant role in enhancing the immunomodulatory activity of different types of MSCs as demonstrated by the increased secretion of PGE2, IDO1, HGF and TGF- $\beta$. Immune responses are bio-energetically expensive, requiring precise control of cellular metabolic pathways. A metabolic pathway by which MSCs may modulate immunity has been addressed 

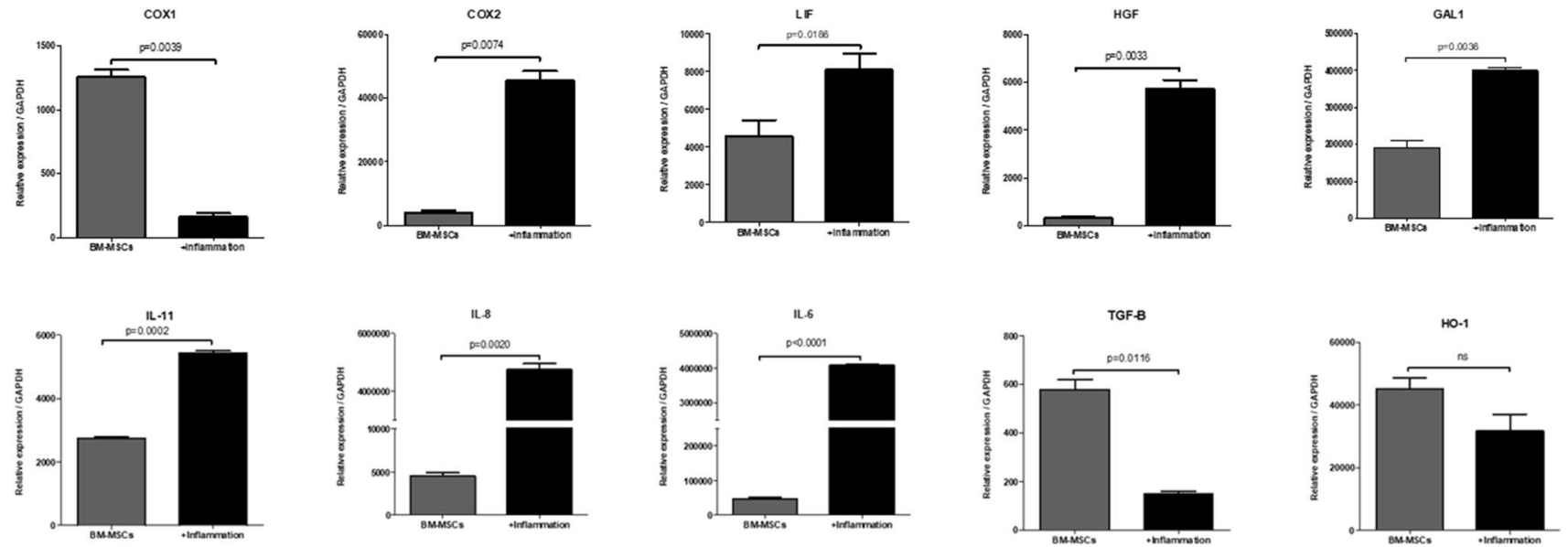

Fig. 3 Immunoregulatory gene profiling of BM-MSCs. The gene mation). The data (mean $\pm \mathrm{SEM}$ ) represent the relative expression of expression pattern of several regulatory mediators was assessed by the respective target gene versus a housekeeping (GAPDH) gene qPCR under constitutive (BM-MSCs) or priming conditions (inflam-
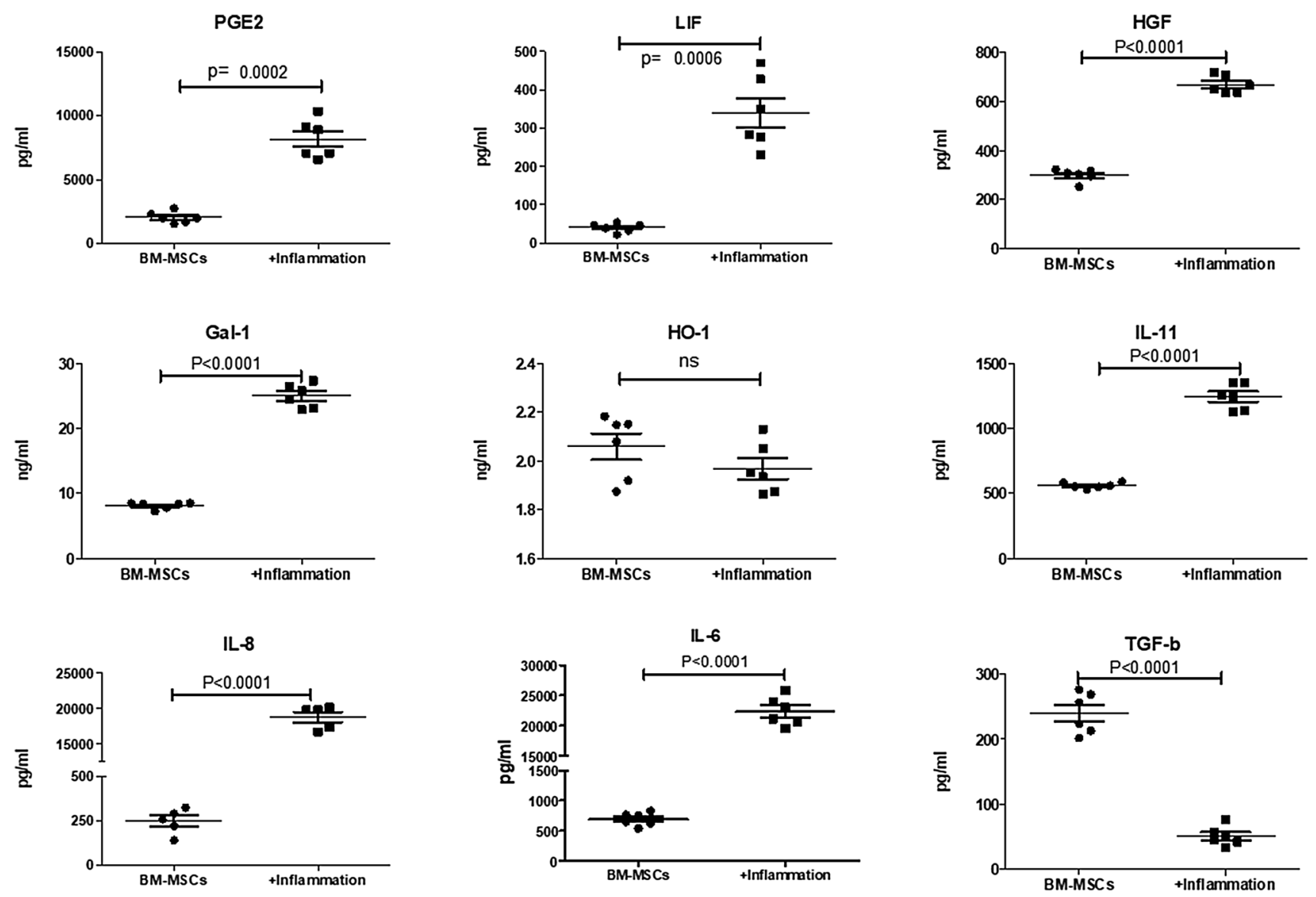

Fig. 4 Immunoregulatory protein profiling of BM-MSCs. The secretion pattern of several regulatory mediators was assessed by ELISA under constitutive (BM-MSCs) or priming conditions (inflammation).
The data (mean \pm SEM) represent the concentration of the respective target protein 
to heme oxygenase-1 (HO-1) expression. $\mathrm{HO}-1$ is an inducible enzyme referred as a stress-responsive, cyto-protective and immunoregulatory molecule. It confers homeostatic protection against various stress-related conditions through the metabolism of free heme into labile iron, carbon monoxide and biliverdin [45]. Although BM-MSCs presented a high constitutive expression of HO-1, inflammatory priming had no significant effect on this expression corroborating thus the conflictual results regarding the contribution of HO-1 to MSC immunomodulatory mechanisms [46].

Prostaglandins (PGs) are small molecule derivatives of arachidonic acid, produced by cyclooxygenases (constitutively active COX1 and inducible COX2) and prostaglandin synthases. As an essential immunoregulatory factor, PGE2 is involved in the regulation of different stages of the immune response [47]. The expression profile COX-1 and COX-2 in BM-MSCs was substantially different. Under constitutive condition, BM-MSCs greatly expressed more COX-1 transcripts than COX-2. Following inflammatory priming, the expression of both cyclooxygenases was inverted as COX-1 was significantly down-regulated whereas that of COX-2 was highly induced. However, the protein level of PGE2 secreted by BM-MSCs, as quantified by ELISA, was substantially increased by inflammation priming. Depending on T-cell stimuli, immunomodulation by MSCs might be ascribed, in part, to COX-derived PGE2 [48, 49]. Current research indicates that galectins may also play important roles in the immune response through regulating the homeostasis and functions of the immune cells. Galectins are a family of animal lectins with affinity for beta-galactosides able to interact with cell-surface and extracellular matrix glycoconjugates through lectin-carbohydrate interaction [50]. Although the expression of galectin was constitutively observed in our settings, inflammation priming significantly up-regulated such expression at both gene and protein levels. Indeed, involvement of MSC-derived galectins in immunomodulation is more complex than thought as different expression profiles and activities have been highlighted [51]. Afterward we evaluated the expression of the leukemia inhibitory factor (LIF), a pleiotropic cytokine linked to the immune tolerance at the maternal-fetal interface [52]. Within BMMSCs, the moderate expression of LIF as observed in basic condition was highly enhanced following inflammatory priming. In agreement with Nasef et al., LIF may be involved as an accessory factor to support MSC immunodulation process [53].

Transforming growth factor $\beta$ (TGF- $\beta$ ) and hepatocyte growth factor (HGF) are among the first immunoregulatory molecules that were demonstrated to actively contribute to MSC inhibition of T-cell response [54]. TGF- $\beta$ and HGF are pleiotropic factors with abilities to regulate several cellular process such as cell growth and differentiation but also to control immune homeostasis [55, 56]. BM-MSCs constitutively expressed HGF and TGF- $\beta$ but at different levels. After inflammatory priming, the expression of HGF was significantly increased whereas that of TGF- $\beta$ was downregulated. A previous research indicated that these two molecules synergistically cooperate to induce $\mathrm{T}$-cell suppression [54]. However, a study has found that MSC-derived TGF- $\beta$ reduces inducible NO synthase expression, therefore, promoting an immune response [57].

This immune homeostasis is harmonized by the direct interactions between immune cells and the cytokine environment. Cytokines affect T-cell activation and differentiation, and in turn regulate immunity and immune tolerance [58]. We observed that the expression profile of cytokines (IL-6 and IL-11) and chemokines (IL-8) by BM-MSCs was different. Although presenting basic elevated expression of IL-11 and IL-8, the expression of IL-6 was the most pronounced. Inflammation priming substantially up-regulated the gene transcription and protein translation of these cytokines and chemokines demonstrating thus their importance in MSC immunomodulation. Functional pleiotropy and redundancy are characteristic features of cytokines, which include interleukins, chemokines, and many growth factors. IL-6 is a cytokine not only involved in inflammation and infection responses but also in the regulation of metabolic, regenerative, and neural processes [59]. IL-6 has context-dependent pro- and anti-inflammatory properties and is now regarded as a prominent target for clinical intervention [60]. There is considerable secretion changes from MSCs in response to inflammatory stimuli indicating that their secretion profile is tightly regulated by environmental challenges [61]. The dual ability of MSCs to either sustain or suppress T-cell proliferation was associated with IL-6 secretion and should be considered in the context of clinical applications [62]. IL-11, a member of the IL-6 cytokine family, exerts pleiotropic activities and is generally considered to be an antiinflammatory cytokine, with the capacity to regulate different immune effector cells [63].

Previous observations demonstrated that IL-11 like MSCs attenuates GVHD (graft versus host disease) while preserves the GVL activity in an experimental model of bone marrow transplantation (BMT) arguing that the effects of MSCs might be mediated through the secretion of IL-11 [64-66]. It is now well recognized that chemokines, together with adhesion molecules, are master controllers of lymphocyte migration and recruitment to inflammatory sites [67]. Particularly in inflammatory settings, the production of high level of chemokines such as IL-8 and CCL5 favors and promotes lymphocyte homing and retention in the surroundings of MSCs facilitating, thus, their immunomodulation [68].

Surprisingly, IFN- $\gamma$ priming of human umbilical cordderived MSCs (hUC-MSCs) induced enhanced protective effects against trinitrobenzene sulfonic acid (TNBS)-induced colitis in mice while TNF- $\alpha$ had no impact [69]. A previous 
study showed that IL-17 acts synergistically with IFN- $\gamma$ and TNF- $\alpha$ to enhance immunosuppression by MSC in mouse models of hepatitis in an iNOS-dependent manner [70]. However, Sivanathan et al. [71] stated that IL-17A priming of MSCs (MSC-17) represents a novel immunomodulatory strategy and an alternative to IFN- $\gamma$ in enhancing the immunosuppressive properties of MSCs while retaining them in an inert immunogenic state. MSC-17, unlike MSC- $\gamma$, showed no induction or upregulation of MHC class I, MHC class II, and T-cell costimulatory molecule CD40 that may negatively affect their fate in vivo. More importantly, in contrast to MSC- $\gamma$, lymphocyte inhibition by MSC-17 involved a distinct mechanism as it was correlated with increased IL- 6 but not with IDO1, COX-1, and TGF- $\beta$.

\section{Conclusions}

Finding the suitable way to enhance the recruitment of MSCs and potentiation of their effector mechanisms will be of great interest to improve the efficiency of MSC therapy [72]. As demonstrated, MSCs actively respond to inflammation and properly adjust their immunoregulatory repertoire. Accordingly, priming with inflammatory cocktail should be used during MSC preparation to promote their regulatory fate and thus allow the selection of highly therapeutic MSCs.

Acknowledgements We gratefully acknowledge the support received from the "Fonds de la Recherche Scientifique (FNRS)", and its Télévie program. We also thank the Canadian Institutes of Health Research (Grant MOP-130293).

\section{Compliance with ethical standards}

Conflict of interest The authors declare that they have no competing interests.

\section{References}

1. Via AG, Frizziero A, Oliva F. Biological properties of mesenchymal stem cells from different sources. Muscles Ligaments Tendons J. 2012;2(3):154-62.

2. Zhao Q, Ren H, Han Z. Mesenchymal stem cells: Immunomodulatory capability and clinical potential in immune diseases. J Cell Immunother. 2016;2(1):3-20.

3. Meirelles Lda S, Fontes AM, Covas DT, Caplan AI. Mechanisms involved in the therapeutic properties of mesenchymal stem cells. Cytokine Growth Factor Rev. 2009;20(5-6):419-27. https://doi. org/10.1016/j.cytogfr.2009.10.002.

4. Wang Y, Chen X, Cao W, Shi Y. Plasticity of mesenchymal stem cells in immunomodulation: pathological and therapeutic implications. Nat Immunol. 2014;15(11):1009-16. https://doi. org/10.1038/ni.3002.

5. Luk F, de Witte SF, Bramer WM, Baan CC, Hoogduijn MJ. Efficacy of immunotherapy with mesenchymal stem cells in man: a systematic review. Expert Rev Clin Immunol. 2015;11(5):61736. https://doi.org/10.1586/1744666X.2015.1029458.

6. Fayyad-Kazan H, Faour WH, Badran B, Lagneaux L, Najar M. The immunomodulatory properties of human bone marrow-derived mesenchymal stromal cells are defined according to multiple immunobiological criteria. Inflamm Res. 2016;65(6):501-10. https://doi.org/10.1007/s0001 1-016-0933-2.

7. Najar M, Raicevic G, Crompot E, Fayyad-Kazan H, Bron D, Toungouz M, et al. The immunomodulatory potential of mesenchymal stromal cells: a story of a regulatory network. J Immunother. 2016;39(2):45-59. https://doi.org/10.1097/CJI.00000 00000000108.

8. Najar M, Raicevic G, Fayyad-Kazan H, Bron D, Toungouz M, Lagneaux L. Mesenchymal stromal cells and immunomodulation: a gathering of regulatory immune cells. Cytotherapy. 2016;18(2):160-71. https://doi.org/10.1016/j.jcyt.2015.10.011.

9. Najar M, Raicevic G, Fayyad-Kazan H, De Bruyn C, Bron D, Toungouz M, et al. Bone marrow mesenchymal stromal cells induce proliferative, cytokinic and molecular changes during the T cell response: the importance of the IL-10/CD210 axis. Stem Cell Rev. 2015;11(3):442-52. https://doi.org/10.1007/ s12015-014-9567-3.

10. Najar M, Raicevic G, Fayyad-Kazan H, De Bruyn C, Bron D, Toungouz M, et al. Immune-related antigens, surface molecules and regulatory factors in human-derived mesenchymal stromal cells: the expression and impact of inflammatory priming. Stem Cell Rev. 2012;8(4):1188-98. https://doi.org/10.1007/s1201 5-012-9408-1.

11. Qi K, Li N, Zhang Z, Melino G. Tissue regeneration: the crosstalk between mesenchymal stem cells and immune response. Cell Immunol. 2018;326:86-93. https://doi.org/10.1016/j.celli mm.2017.11.010.

12. Holan V, Hermankova B, Bohacova P, Kossl J, Chudickova M, Hajkova M, et al. Distinct immunoregulatory mechanisms in mesenchymal stem cells: role of the cytokine environment. Stem Cell Rev. 2016;12(6):654-63. https://doi.org/10.1007/s1201 5-016-9688-y.

13. Murphy MB, Moncivais K, Caplan AI. Mesenchymal stem cells: environmentally responsive therapeutics for regenerative medicine. Exp Mol Med. 2013;45:e54. https://doi.org/10.1038/ emm.2013.94.

14. Bernardo ME, Fibbe WE. Mesenchymal stromal cells: sensors and switchers of inflammation. Cell Stem Cell. 2013;13(4):392402. https://doi.org/10.1016/j.stem.2013.09.006.

15. Najar M, Krayem M, Merimi M, Burny A, Meuleman N, Bron $\mathrm{D}$, et al. Insights into inflammatory priming of mesenchymal stromal cells: functional biological impacts. Inflamm Res. 2018;67(6):467-77. https://doi.org/10.1007/s0001 1-018-1131-1.

16. Feghali CA, Wright TM. Cytokines in acute and chronic inflammation. Front Biosci. 1997;2:d12-26.

17. Last-Barney K, Homon CA, Faanes RB, Merluzzi VJ. Synergistic and overlapping activities of tumor necrosis factor-alpha and IL-1. J Immunol. 1988;141(2):527-30.

18. Schroder K, Hertzog PJ, Ravasi T, Hume DA. Interferon-gamma: an overview of signals, mechanisms and functions. J Leukoc Biol. 2004;75(2):163-89. https://doi.org/10.1189/jlb.0603252.

19. Dominici M, Le Blanc K, Mueller I, Slaper-Cortenbach I, Marini F, Krause D, et al. Minimal criteria for defining multipotent mesenchymal stromal cells. The International Society for Cellular Therapy position statement. Cytotherapy. 2006;8(4):315-7. https ://doi.org/10.1080/14653240600855905.

20. Pankajakshan D, Agrawal DK. Mesenchymal stem cell paracrine factors in vascular repair and regeneration. J Biomed Technol Res. 2014. https://doi.org/10.19104/jbtr.2014.107. 
21. Ma S, Xie N, Li W, Yuan B, Shi Y, Wang Y. Immunobiology of mesenchymal stem cells. Cell Death Differ. 2014;21(2):216-25. https://doi.org/10.1038/cdd.2013.158.

22. Ryan JM, Barry FP, Murphy JM, Mahon BP. Mesenchymal stem cells avoid allogeneic rejection. J Inflamm (Lond). 2005;2:8. https://doi.org/10.1186/1476-9255-2-8.

23. Bourin P, Bunnell BA, Casteilla L, Dominici M, Katz AJ, March $\mathrm{KL}$, et al. Stromal cells from the adipose tissue-derived stromal vascular fraction and culture expanded adipose tissue-derived stromal/stem cells: a joint statement of the International Federation for Adipose Therapeutics and Science (IFATS) and the International Society for Cellular Therapy (ISCT). Cytotherapy. 2013;15(6):641-8. https://doi.org/10.1016/j.jcyt.2013.02.006.

24. Suga H, Matsumoto D, Eto H, Inoue K, Aoi N, Kato H, et al. Functional implications of CD34 expression in human adipose-derived stem/progenitor cells. Stem Cells Dev. 2009;18(8):1201-10. https://doi.org/10.1089/scd.2009.0003.

25. W PMSHRMMG. SK. Adult mesenchymal stem cells and cell surface characterization-a systematic review of the literature. Open Orthop J. 2011;5(Suppl 2):253-60. https://doi. org/10.2174/1874325001105010253.

26. Najar M, Raicevic G, Andre T, Fayyad-Kazan H, Pieters K, Bron D, et al. Mesenchymal stromal cells from the foreskin: tissue isolation, cell characterization and immunobiological properties. Cytotherapy. 2016;18(3):320-35. https://doi. org/10.1016/j.jcyt.2015.11.013.

27. Sundin M, D’Arcy P, Johansson CC, Barrett AJ, Lonnies H, Sundberg B, et al. Multipotent mesenchymal stromal cells express FoxP3: a marker for the immunosuppressive capacity? J Immunother. 2011;34(4):336-42. https://doi.org/10.1097/ CJI.0b013e318217007c.

28. Regateiro FS, Cobbold SP, Waldmann H. CD73 and adenosine generation in the creation of regulatory microenvironments. Clin Exp Immunol. 2013;171(1):1-7. https://doi.org/10.111 $1 / \mathrm{j} .1365-2249.2012 .04623 . x$.

29. Lee JJ, Jeong HJ, Kim MK, Wee WR, Lee WW, Kim SU, et al. CD39-mediated effect of human bone marrow-derived mesenchymal stem cells on the human Th17 cell function. Purinergic Signal. 2014;10(2):357-65. https://doi.org/10.1007/s1130 2-013-9385-0.

30. Szyska M, Na IK. Bone marrow GvHD after allogeneic hematopoietic stem cell transplantation. Front Immunol. 2016;7:118. https://doi.org/10.3389/fimmu.2016.00118.

31. Wood KJ, Issa F, Hester J. Understanding stem cell immunogenicity in therapeutic applications. Trends Immunol. 2016;37(1):5-16. https://doi.org/10.1016/j.it.2015.11.005.

32. Le Blanc K, Tammik C, Rosendahl K, Zetterberg E, Ringden O. HLA expression and immunologic properties of differentiated and undifferentiated mesenchymal stem cells. Exp Hematol. 2003;31(10):890-6.

33. Romieu-Mourez R, Francois M, Boivin MN, Stagg J, Galipeau J. Regulation of MHC class II expression and antigen processing in murine and human mesenchymal stromal cells by IFN-gamma, TGF-beta, and cell density. J Immunol. 2007;179(3):1549-58.

34. Kim JH, Jo CH, Kim HR, Hwang YI. Comparison of immunological characteristics of mesenchymal stem cells from the periodontal ligament, umbilical cord, and adipose tissue. Stem Cells Int. 2018;2018:8429042. https://doi.org/10.1155/2018/8429042.

35. Frauwirth KA, Thompson CB. Activation and inhibition of lymphocytes by costimulation. J Clin Invest. 2002;109(3):295-9. https ://doi.org/10.1172/JCI14941.

36. Briones J, Novelli S, Sierra J. T-cell costimulatory molecules in acute-graft-versus host disease: therapeutic implications. Bone Marrow Res. 2011;2011:976793. https://doi. org/10.1155/2011/976793.
37. Castro-Manrreza ME, Mayani H, Monroy-Garcia A, FloresFigueroa E, Chavez-Rueda K, Legorreta-Haquet V, et al. Human mesenchymal stromal cells from adult and neonatal sources: a comparative in vitro analysis of their immunosuppressive properties against T cells. Stem Cells Dev. 2014;23(11):1217-32. https ://doi.org/10.1089/scd.2013.0363.

38. Ankrum JA, Ong JF, Karp JM. Mesenchymal stem cells: immune evasive, not immune privileged. Nat Biotechnol. 2014;32(3):25260. https://doi.org/10.1038/nbt.2816.

39. Kyurkchiev D, Bochev I, Ivanova-Todorova E, Mourdjeva M, Oreshkova T, Belemezova K, et al. Secretion of immunoregulatory cytokines by mesenchymal stem cells. World J Stem Cells. 2014;6(5):552-70. https://doi.org/10.4252/wjsc.v6.i5.552.

40. Shi Y, Cao J, Wang Y. Rethinking regeneration: empowerment of stem cells by inflammation. Cell Death Differ. 2015;22(12):18912. https://doi.org/10.1038/cdd.2015.127.

41. Prasanna SJ, Gopalakrishnan D, Shankar SR, Vasandan AB. Pro-inflammatory cytokines, IFNgamma and TNFalpha, influence immune properties of human bone marrow and Wharton jelly mesenchymal stem cells differentially. PLoS One. 2010;5(2):e9016. https://doi.org/10.1371/journal.pone.0009016.

42. Crop MJ, Baan CC, Korevaar SS, Ijzermans JN, Pescatori M, Stubbs AP, et al. Inflammatory conditions affect gene expression and function of human adipose tissue-derived mesenchymal stem cells. Clin Exp Immunol. 2010;162(3):474-86. https://doi.org/10 .1111/j.1365-2249.2010.04256.x.

43. Krampera M, Cosmi L, Angeli R, Pasini A, Liotta F, Andreini A, et al. Role for interferon-gamma in the immunomodulatory activity of human bone marrow mesenchymal stem cells. Stem Cells. 2006;24(2):386-98. https://doi.org/10.1634/stemcells.2005-0008.

44. Chen K, Wang D, Du WT, Han ZB, Ren H, Chi Y, et al. Human umbilical cord mesenchymal stem cells hUC-MSCs exert immunosuppressive activities through a PGE2-dependent mechanism. Clin Immunol. 2010;135(3):448-58. https://doi.org/10.1016/j. clim.2010.01.015.

45. Chabannes D, Hill M, Merieau E, Rossignol J, Brion R, Soulillou $\mathrm{JP}$, et al. A role for heme oxygenase- 1 in the immunosuppressive effect of adult rat and human mesenchymal stem cells. Blood. 2007;110(10):3691-4. https://doi.org/10.1182/blood-2007-02075481.

46. Patel SR, Copland IB, Garcia MA, Metz R, Galipeau J. Human mesenchymal stromal cells suppress T-cell proliferation independent of heme oxygenase-1. Cytotherapy. 2015;17(4):382-91. https ://doi.org/10.1016/j.jcyt.2014.11.010.

47. Kalinski P. Regulation of immune responses by prostaglandin E2. J Immunol. 2012;188(1):21-8. https://doi.org/10.4049/jimmu nol.1101029.

48. Rasmusson I, Ringden O, Sundberg B, Le Blanc K. Mesenchymal stem cells inhibit lymphocyte proliferation by mitogens and alloantigens by different mechanisms. Exp Cell Res. 2005;305(1):33-41. https://doi.org/10.1016/j.yexcr.2004.12.013.

49. Hsu WT, Lin CH, Chiang BL, Jui HY, Wu KK, Lee CM. Prostaglandin E2 potentiates mesenchymal stem cell-induced IL-10+ IFN-gamma+ CD4+ regulatory T cells to control transplant arteriosclerosis. J Immunol. 2013;190(5):2372-80. https://doi. org/10.4049/jimmunol.1202996.

50. Liu FT. Regulatory roles of galectins in the immune response. Int Arch Allergy Immunol. 2005;136(4):385-400. https://doi. org/10.1159/000084545.

51. Sioud M, Mobergslien A, Boudabous A, Floisand Y. Mesenchymal stem cell-mediated $\mathrm{T}$ cell suppression occurs through secreted galectins. Int J Oncol. 2011;38(2):385-90. https://doi. org/10.3892/ijo.2010.869.

52. Nicola NA, Babon JJ. Leukemia inhibitory factor (LIF). Cytokine Growth Factor Rev. 2015;26(5):533-44. https://doi.org/10.1016/j. cytogfr.2015.07.001. 
53. Nasef A, Mazurier C, Bouchet S, Francois S, Chapel A, Thierry $\mathrm{D}$, et al. Leukemia inhibitory factor: role in human mesenchymal stem cells mediated immunosuppression. Cell Immunol. 2008;253(1-2):16-22. https://doi.org/10.1016/j.celli mm.2008.06.002.

54. Di Nicola M, Carlo-Stella C, Magni M, Milanesi M, Longoni PD, Matteucci P, et al. Human bone marrow stromal cells suppress T-lymphocyte proliferation induced by cellular or nonspecific mitogenic stimuli. Blood. 2002;99(10):3838-43.

55. Skibinski G. The role of hepatocyte growth factor/c-met interactions in the immune system. Arch Immunol Ther Exp (Warsz). 2003;51(5):277-82.

56. Li MO, Wan YY, Sanjabi S, Robertson AK, Flavell RA. Transforming growth factor-beta regulation of immune responses. Annu Rev Immunol. 2006;24:99-146. https://doi.org/10.1146/annur ev.immunol.24.021605.090737.

57. Xu C, Yu P, Han X, Du L, Gan J, Wang Y, et al. TGF-beta promotes immune responses in the presence of mesenchymal stem cells. J Immunol. 2014;192(1):103-9. https://doi.org/10.4049/ jimmunol.1302164.

58. Wu J, Xie A, Chen W. Cytokine regulation of immune tolerance. Burns Trauma. 2014;2(1):11-7. https://doi.org/10.4103/23213868.124771.

59. Scheller J, Chalaris A, Schmidt-Arras D, Rose-John S. The pro- and anti-inflammatory properties of the cytokine interleukin-6. Biochim Biophys Acta. 2011;1813(5):878-88. https://doi. org/10.1016/j.bbamcr.2011.01.034.

60. Hunter CA, Jones SA. IL-6 as a keystone cytokine in health and disease. Nat Immunol. 2015;16(5):448-57. https://doi. org/10.1038/ni.3153.

61. Zhukareva V, Obrocka M, Houle JD, Fischer I, Neuhuber B. Secretion profile of human bone marrow stromal cells: donor variability and response to inflammatory stimuli. Cytokine. 2010;50(3):317-21. https://doi.org/10.1016/j.cyto.2010.01.004.

62. Najar M, Rouas R, Raicevic G, Boufker HI, Lewalle P, Meuleman N, et al. Mesenchymal stromal cells promote or suppress the proliferation of $\mathrm{T}$ lymphocytes from cord blood and peripheral blood: the importance of low cell ratio and role of interleukin-6. Cytotherapy. 2009;11(5):570-83. https://doi.org/10.1080/14653 240903079377.

63. Putoczki T, Ernst M. More than a sidekick: the IL-6 family cytokine IL-11 links inflammation to cancer. J Leukoc Biol. 2010;88(6):1109-17. https://doi.org/10.1189/jlb.0410226.
64. Hill GR, Cooke KR, Teshima T, Crawford JM, Keith JC Jr, Brinson YS, et al. Interleukin-11 promotes $\mathrm{T}$ cell polarization and prevents acute graft-versus-host disease after allogeneic bone marrow transplantation. J Clin Invest. 1998;102(1):115-23. https ://doi.org/10.1172/JCI3132.

65. Teshima T, Hill GR, Pan L, Brinson YS, van den Brink MR, Cooke KR, et al. IL-11 separates graft-versus-leukemia effects from graft-versus-host disease after bone marrow transplantation. J Clin Invest. 1999;104(3):317-25. https://doi.org/10.1172/JCI71 11.

66. Auletta JJ, Eid SK, Wuttisarnwattana P, Silva I, Metheny L, Keller $\mathrm{MD}$, et al. Human mesenchymal stromal cells attenuate graftversus-host disease and maintain graft-versus-leukemia activity following experimental allogeneic bone marrow transplantation. Stem Cells. 2015;33(2):601-14. https://doi.org/10.1002/ stem. 1867.

67. Moser B, Wolf M, Walz A, Loetscher P. Chemokines: multiple levels of leukocyte migration control. Trends Immunol. 2004;25(2):75-84. https://doi.org/10.1016/j.it.2003.12.005.

68. Najar M, Raicevic G, Fayyad-Kazan H, De Bruyn C, Bron D, Toungouz M, et al. Impact of different mesenchymal stromal cell types on T-cell activation, proliferation and migration. Int Immunopharmacol. 2013;15(4):693-702. https://doi.org/10.1016/j.intim p.2013.02.020.

69. Qiu Y, Guo J, Mao R, Chao K, Chen BL, He Y, et al. TLR3 preconditioning enhances the therapeutic efficacy of umbilical cord mesenchymal stem cells in TNBS-induced colitis via the TLR3Jagged-1-Notch-1 pathway. Mucosal Immunol. 2017;10(3):72742. https://doi.org/10.1038/mi.2016.78

70. Han X, Yang Q, Lin L, Xu C, Zheng C, Chen X, et al. Interleukin-17 enhances immunosuppression by mesenchymal stem cells. Cell Death Differ. 2014;21(11):1758-68. https://doi.org/10.1038/ cdd.2014.85.

71. Sivanathan KN, Rojas-Canales DM, Hope CM, Krishnan R, Carroll RP, Gronthos S, et al. Interleukin-17A-induced human mesenchymal stem cells are superior modulators of immunological function. Stem Cells. 2015;33(9):2850-63. https://doi.org/10.1002/ stem.2075.

72. Kavanagh DP, Robinson J, Kalia N. Mesenchymal stem cell priming: fine-tuning adhesion and function. Stem Cell Rev. 2014;10(4):587-99. https://doi.org/10.1007/s12015-014-9510-7. 